\title{
Evaluating Employee Retention Strategies on Job Performance
}

\author{
Ibrahim Abdulai Sawaneh ${ }^{1, ~ *, ~ F a t m a t a ~ K a n k o ~ K a m a r a ~}{ }^{2}$ \\ ${ }^{1}$ Department of Computer Science at the Ernest Bai Koroma University of Science and Technology, Magburaka, Sierra Leone \\ ${ }^{2}$ Sierra Leone Peacekeeping and Law Enforcement Academy (SILEA), Hastings Police Training School, Hastings, Sierra Leone
}

Email address:

ciddiisawaneh@hotmail.com (I. A. Sawaneh)

${ }^{*}$ Corresponding author

\section{To cite this article:}

Ibrahim Abdulai Sawaneh, Fatmata Kanko Kamara. Evaluating Employee Retention Strategies on Job Performance. Science Journal of Business and Management. Vol. 7, No. 3, 2019, pp. 67-73. doi: 10.11648/j.sjbm.20190703.12

Received: July 24, 2019; Accepted: August 19, 2019; Published: August 29, 2019

\begin{abstract}
Due to the increasing demand in the job market as a result of several job opportunities, good employee retention strategies are vital for achieving organizational success and performance. Considering skilled and innovative employees leaving an organization, will subsequently have negative effects on the organization's survival. Employees normally abandoned their jobs when they feel dissatisfied and de-motivated by either their supervisor and /or other de-motivating factors such as low salary, annual leave allowance, maternity leave, rewards and incentives, remuneration, politics, poor communication among employees, lack of respect to employees by supervisor and management, undermining organizational culture by supervisor, training, and others. This will lead to an employer to loose valuable and determined employees to rivals in job market, loss of corporate memory, fracture employee customer relationship and most importantly, the moral standing of the organization goes down to the drain. Therefore, it is essential for an organization to retain the most valuable and experienced employees. Employee retention is referred to a method where employees are motivated to stay longer working in an organization, or for a specified timeframe of a project execution. The study examines the role of HR policies in retaining valuable employees in an organization. It further try to bridge the communication gap between employers and employees on salient issues in the organization by maintaining skilled and innovative employees of the organization for infinite time. The research also indicated that, green pasture, lack of opportunities, work-life balance, lack of recognition, low salary scale, poor reward and remuneration system, and study leave were among some of the reasons employees leave their jobs for better opportunities elsewhere. Retaining skillful and innovative employees should be of the utmost priority for all organizations and good retention strategies should be intended to retain highly innovative and talented employees. Motivation and free flow of communications produces best cultural commitment that will ultimately achieve organizational blueprint.
\end{abstract}

Keywords: Employee Retention, Organizational Performance, Motivation, Retention Strategies

\section{Introduction}

Employment in the colonial period were almost for life, which is quite different in today's business world. Employees normally spent their entire life in those jobs until their retirement age and employers treated their employees with justness and fairness, and employees in turn were completely loyal to their employers. Employees invest their entire energy to promote the wellbeing of those organizations. Job retention is a big challenge in post Ebola Sierra Leone, especially in the private sector and few instances in the public sector. Organizations in the public sector normally do not follow effective retention strategies that will encourage valuable and talented employees to stay in a particular organization. In order to retain such employees, organization has to be creative and innovative in designing effective and efficient retention strategies that will encourage valuable employees to stay longer, and invest their God giving talents into the organization's performance. They should also create a conducive working atmosphere where employees have a sense of belonging, as they give their inputs before reaching the final decision. Top management and supervisors should also create a continuous communication platform where all 
employees are inform of their expected duties and responsibilities, work in harmony, provide psychological advice to depressed employees, provide incentives and other motivational packages to hardworking and dedicated employees, as they are the foot soldiers performing the daily activities for the organization.

Smith suggested that several factors are considered for an employee to leave a particular job. It could either be on a voluntary basis where the employee decides to leave for reason best known to the aggrieved employee. It could also be for other reasons such as lack of advanced career development opportunities, poor incentive and compensation schemes, over loaded with multiple tasks, and others. Involuntary turnover results to an employee leaving their jobs upon the request from their employer, with reasons such as not meeting the expectation on job performance, and / or inappropriate behaviour. Most private organizations in Sierra Leone lack the basic motivational tips such as retirement benefits, high salary pay, better remuneration attached to top management positions, organizational culture, career development opportunities, and interference. Recruiting new employee inflicts additional cost directly or indirectly on the organization.

Most organizations respond to employee turnover when its effects are felt and prompt immediate response. Providing motivational tips such as allocating time for employees to allocate some time for family purpose, performance reviews and performance based salary upgrade along with traditional benefits such as paid holidays and sick leave allowance, which helps maintain and retain employee retention.

Generally, employee carried with them the organization's skills, cultures, experience and corporate memory when they leave a particular organization. The degree and nature of such organizational loss has a dire consequences on the management operations and successes, thereby hiring productivity, profitability, and services.

Failing to practice best retention strategy exposes an organization to huge difficulties with regards to finance and employees' turnover. Organizations should apply both conventional and modern business approaches in order to sway dedicated and talented employee to stay for the good of the organizational success. The mixture of the two approaches will ultimately enhance employees' job performance, turnover and increase organizational profitability. Furthermore, with e-business, e-recruitment, and other forms of internet business place jobs at our doorsteps due to globalization and internet revolution in business world. Jobs are constantly been advertised on social media sites breaking the barrier where ones only depend on print media for jobs adverts. Therefore, organization should diverse mechanisms that will attract and at the same time discourage them from leaving by allowing communication to flow in both ways, and incentivized committed and innovative workers.

\section{Statement of the Problem}

The high demand for valuable employees deployed in highly demanded infrastructure such as educational institution, healthcare sector, IT industries, engineering field, banking sector, and logistical operations. Recruiting qualified and professional employees are critical and hence having productive workforce requires effective strategies in massive recruitment and innovative strategies in retaining valuable employees. Retaining talented employees especially in the private sector is crucial due to the fact that they are lured by the public sector because of the security and benefits attached to government appointment. Therefore, the research was conducted to suggest creative and innovative schemes that will help retain valuable employees and motivate underperformers to achieve their full potentials for organizational success.

\section{Objectives of the Research}

The following objectives were coined for the research as follows:

1. To reference numerous works done with regard to employee retention.

2. To examine the factors that affect employee retention strategies.

3. To study the several factors that affect employee retention strategy and job satisfaction.

4. To determine the effect of employee retention strategies and policies in an organization.

\section{Methodology}

The methodology used is descriptive and utilizes only secondary data. The secondary data includes the internet, business journals and textbooks on employee retention policies and strategies.

\section{Literature Review}

Retaining talented and skillful employees in an organization is challenging and pose a great threat to modern organizations. Successful organizations spend their energy, time, money, and effort to ensure that they retain the most talented and innovated employees. There are numerous reasons which prompt employees to voluntarily quit their jobs. The problem of turnover should be overcome as it imposes huge costs on both individuals and organizations [1]. Management spend quite a lot on the employees with regards to motivating, recruiting, retaining, and career developing. Organizations should implement a preventive measures that avert or minimize employee's turnover. Employee retention is a critical issue and has no proven solutions yet; so several schemes have been suggested to understand employee turnover [2].

According to Chipunza and Samuel [3] stressed that both private and public sectors are faced with challenges to retain talented employees. Managers in the private sector acknowledge that retaining essential employees in the organization is the most difficult job. Normally, employees 
quit organizations with lot of details to rivalry organizations such trade secrets, organizational culture, and other knowledgeable critical information learnt from their previous workplaces, prompting a dire situation for the former bosses. This situation requires that senior management to detect the reasons for frequent turnover in an organization. Once this reasons has been identified, senior management can then designed effective retention strategies and policies that help retaining valuable employees for a longer period of time.

To minimize or eradicate retention dilemma is a challenging task for organization. It cannot be solved merely through monetary incentives. When formulating an organizational retention strategy, decision makers should always take into consideration of on-the-job and off-the-job factors. Such organizations should conduct a survey to identify those critical factors, which force employees to leave quit their jobs in those organizations [1]. Organizations should adopt a retention strategy that combines organization's unique culture, salary, rewards, compensation, bonuses, and appreciate talents making them feel essential to the organization's operations [4].

\section{Factors Affecting Employees Retention}

There exist several schemes that minimize employee turnover in an organization. Management are required to identify the factors that prompt employees to quit their jobs in order to prevent it reoccurring again as it has direct or indirect costs incurred on the employees' turnover [5]. Failing to retain committed and hardworking employees could be critical to survival of the organizations. Series of research has been conducted by several organizations to identify the effect of best human resource practices on employee retention. This research enhances organizations to develop a conducive working environment where employees cultivate positive attitudes that make them stay longer in the organization. They include fair reward system for employees exceeding normal duties, appreciation of contributions made by employees, making the work of employees' inspiring, and providing opportunities for career development programmes. These HR practices can help the employee to decide whether to quit or continue working in the organization [6].

\subsection{Training and Development}

Training and development scheme helps boost retention by meeting the needs of the employees [7]. Fulfilling employee needs through training programmes prevail when the information transferred is taking as essential, appropriate and needed by the employees. It further suggests solutions to retention include: career development, managerial competency, recognition, and rewards both psychological and financial. Organizations should attentively put more money on training and development in order to retain valuable employees. A successful retention strategy must include training [8]. Training motivates employees to stay longer in an organization. Professional training and career development schemes should be incorporated into organizational policies and strategies to serve as a tool to retain employee for longer period of time.

Several organizations nowadays invest hugely on career development programmes to boost organizational performance and retain most valuable employees. Several studies has been conducted on HR practices, which suggest that training and career development programmes are vital for employee's development [9], and organization can benefit greatly from these programmes and increase the organizational productivity. Barringer et al [10], made a comparison between firms with rapid growth and slow growth, and suggests that organizations greatly dependent on the abilities of valuable employees to maintain steady growth. The employees of such organizations invest their entire efforts to maintain the organizational growth strategies in place. In order to attain organizational strategic objectives, successful organizations extensively use training programmes for their employees to meet the demand of the present job market. They viewed employee career development programmes as compared to their non-growing competitors. It is also vital just like focusing on policies and standards that contribute to employee retention [11].

\subsection{Compensation}

One of the tools organization uses to retain its employee is compensation. It serves as a major factor showing the commitment towards employees, and essentially among the convincing reasons employee to stay in an organization. However, monetary incentive alone is not enough to motivate employees to stay in an organization. They may choose to quit for improved monetary benefits, but it is always not proven that improved salary will ensure employees to work longer time for an organization. There are other factors that negatively affect employee's retention in an organization. The factors necessarily affect employee's commitment and demotivate them to quit the organization, thereby suggesting careful consideration to these factors.

Remuneration provides the basis where employee and employer relationship is determined and indicates the expression of appreciation from an employee [12]. The rampant rivalry among organizations reflect the need to retain skillful and hardworking employee to enhance organizational sustainability. Organizations compete for talented employees to gain competitive edge in the market.

Compensation acts as a factor in retaining talented employee and therefore, most successful organizations premium it in the form of security plans, scholarships, medical allowance, career development, stock options and others. Some prominent organizations do profit sharing and group-based incentive plans [6]. A broadly used procedure adopted by several managers to boost employee retention is grounded on performance compensation, rewards after evaluation of employee's performance [13].

\subsection{Organizational Culture}

Organizational culture is a set of beliefs, values and 
behaviours organization cultivate or discover to address issues, and acts as a guide to new recruits for solving problems [14]. Culture differs among organizations and constitutes of norms and values portrayed by members within an organization, which is inherited by new recruits. Guiding employees at workplace of what they are to do and don't help minimize risk. However, culture keeps changing to reflect environmental changes and new thoughts, beliefs and feelings get in it with the passage of time [15]. Organizations must try to harmonize different cultures and select the best that create conducive environment for its employees, and must always consider it when designing the organizational strategy plan to boost retention.

\subsection{Skill Recognition}

Identifying and providing the required skills for talented employees help boost employee's retention strategy at any age [16]. Yazinski [16] in 2009 shows larger number of job seekers looking for organizations that encourage employee's input, growth, education, and teamwork, different from oldstyle compensation schemes initiated by employers.

\subsection{Benefits}

Most private organizations ignore benefits, and benefits prompt employees to stay longer in an organization according to researchers. It make employees believe that the organization is supportive and just, and there is a signal indicating unchangeable remunerations strategies that will either encourage employee to stay or leave for rivalry organization [17]. However, some employees most often ignore the numerous remunerations they receive, and also ignore to acknowledge what motivated the employer to offer such benefits. In a note shell, indicating the relationship between benefits and employee's commitment in stronger bond. Frequent communication between employees and senior managements is crucial for retaining valuable employees [18].

\subsection{Skill-based Pay}

In a skill-based pay system, employees are being paid according their skills and experience, and here the organization pays the skilled and experienced employees rather than the job position. It enhances organizations to fulfil its skill requirements and motivate employees to learn specific skills good for organizational development. The key merit here is that it promotes flexibility. This enhance individual employees to perform several tasks. Skill-based pay scheme results to lesser turnover as such employees will only be given more remunerations based on their innovative skills, and will be almost impossible to get one in an organizations using more traditional job-based pay systems.

\subsection{Recruitment and Orientation}

Several literatures seems to confirm that effective retention is about more than what an organization does once an employee has been recruited. How organizations recruit and how they make available the necessary information to newcomers help motivate employees to stay on a long term basis. Failing to successfully recruit and orientate employees may inflict major costs on the organization. According to Jackofsky [19], about $60 \%$ of unwanted turnovers are attributed to wrong recruitments on the part of the employer. Wrong/bad recruitment policies such as failing to consider the selection process based on merit, and other recruitment criteria may adversely affect the growth and success of the organization.

\subsection{Work-life Balance}

Work-life balance programmes helps to reduce conflict within an organization. It covers several schemes such as dependent care leave, childcare subsidies, eldercare programmes, counseling and referral, and flexible working hours [20]. Allowing employees to have some leisure time with family and friends enhances a well work-life balance, though it will compete with their professional commitments; therefore, it is essential to allow employees to make a meaningful less stressful balance between official tasks and tasks at home. According to Lockwood [21], there were several conflicts in the $1990 \mathrm{~s}$ in the above narration. Jobs were more stressful and employees usually show less commitment to their employers and high absentee from work.

\subsection{Communications}

Failing to allow communication to flow from top - bottom and bottom - top approach hinders job turnover in an organization. Any management that practices open, responsive, and two-way communications stand to be able to manage or retain talented employee for a long timeframe. Communication is the bedrock upon which all the other job retention practices can be successful. All other HR practices that make organization to be successful rest on solid communication tools without which employees will remain in the dark. Allowing communications to flow among the employees help the organization to amicably resolve disputes among employees and make them stay longer in an organization.

\subsection{Performance Appraisal}

Performance appraisal is vital for all modern organizations. Organizations most always make managerial decisions fairly based on the results of individual's performance. Promotions, transfers, incentives and rewards, career development, termination, training, and other motivational retention schemes should be based on performance appraisals. However, HR policies rest on open communication and better employee commitment. Performance appraisals allow objectives and values to be effectively communicated to employees, in order to enhance a steady stream of critical feedback on the organizational operations. Performance appraisal system together with career development programmes, and other HR policies can 
be a successful retention tool for organizational success.

Other factors not mentioned are: performance-based compensation (incentive pay, merit pay), gain sharing, profit sharing, retention-based compensation, team-based pay, reward and recognition, employee participation, performance management, Knowledge management and knowledge transfer, healthy workplace \& well-being, job design \& teamwork programmes and host of other techniques.

\section{Results \& Discussion}

It is evidence from the research that most private organizations in Sierra Leone do not adhere to best practice that enhance job performance. To achieve higher job performance in an organization requires effective performance appraisal system operation. By carefully appraising dedicated and hardworking innovative staff motivate them to do more and also grant them the confidence to stay longer in that organization. Since retention is a big challenge more especially in developing countries. Since there exist several factors that motivate employees to stay put in an organizations, yet there have been no ultimate factors that can solve employee turnover in an organization. Organizations have different cultures and norms, so do the people running them with different educational background, region, race, and environmental factors that can influence on their reasoning. What might have worked for a particularly organization might work for others. Carefully identifying what discourages employee leaving an organization is paramount especially those talented and innovative employees who know the secrets and cultures of their organizations. Letting go will subsequently be catastrophic financially and ethically. Such disgruntle employees having full insights into the organization's vital documents will be risky as rivalry organizations use such opportunities to win the market. More importantly, recruiting and training of replacements will be costly on the organization. Table 1 below shows a typical institution in Sierra Leone with employees quitting their jobs from 2016 to 2019 with reasons such as resignation, involuntarily termination, study leave and death.

Table 1. The rate of employee leaving job.

\begin{tabular}{lllll}
\hline Categories & Administration & Teaching Staff & Supporting Staff & Reason (s) \\
\hline Senior Management & 13 & 9 & 3 & Resignation/termination/study leave \\
Junior Management & 3 & 12 & 4 & Resignation/termination \\
\hline
\end{tabular}

Table 1 shows that due to the massive number of employees leaving their jobs in a particular institution from 2016 - 2019 has one way or the other had negative effects on job performance. With so many employees abandoning the jobs, more especially the talented and dedicated ones hinder the smooth operations costing millions of Leones. With senior administrative staff (13), and teaching staff (9) leaving have caused set back to the daily managerial functions. The institution has to suffer to recruit such dedicated and hardworking staff who are willing to sacrifice their time to ensure that the organizational benchmarks are met within the specified timeframe.

Table 2. Job satisfaction level.

\begin{tabular}{llllll}
\hline Categories & Highly satisfied & Satisfied & Neutral & Dissatisfied & Total \\
\hline Senior Management & 5 & 15 & 3 & 15 & 38 \\
Junior Management & 10 & 17 & 5 & 30 & 62 \\
Total & 32 & 8 & 45 & 100 \\
\hline
\end{tabular}

It is noted that five (5) senior management were highly satisfied, fifteen (15) satisfied, three (3) neutral, fifteen (15) dissatisfied. This shows that both satisfied and dissatisfied score the same point and that more should be done to persuade senior management to fully commit their skills and energy into the success of the organization. About forty five (45) junior staff were dissatisfied suggesting that the management of those private institutions in Sierra Leone should practice best employee retention strategies to boost the performance of their employees.

Table 3. Employees' Performance Scheme.

\begin{tabular}{llllllc}
\hline Categories & $\begin{array}{l}\text { Training } \\
\text { (Yearly) }\end{array}$ & $\begin{array}{l}\text { Workshop } \\
\text { (Yearly) }\end{array}$ & $\begin{array}{l}\text { Reward } \\
\text { (Yearly) }\end{array}$ & $\begin{array}{l}\text { Incentives } \\
\text { (Yearly) }\end{array}$ & $\begin{array}{l}\text { Promotion } \\
\text { (Yearly) }\end{array}$ & $\begin{array}{l}\text { Termination/Resignation } \\
\text { (Yearly) }\end{array}$ \\
\hline $\begin{array}{l}\text { Senior } \\
\text { Management }\end{array}$ & 2 & 1 & 2 & 8 & 7 & 13 \\
$\begin{array}{l}\text { Junior } \\
\text { Management }\end{array}$ & 1 & 1 & 4 & 14 & 8 & 15 \\
$\begin{array}{l}\text { Supporting Staff } \\
\text { Total }\end{array}$ & 0 & 0 & 0 & 10 & 0 & 43 \\
\hline
\end{tabular}

Table 3 gives analysis on performance parameters in private institutions in Sierra Leone. In order to achieve high performance with regards to jobs performance, organizations should maintain skillful and innovative employee who have passion for organizational growth. This is done by adhering to factors that encourage employees to stay dedicated to the success of those organizations. Thirteen (13) senior staff quit their job yearly either through termination/resignation. More 
trainings, workshops, rewards and incentives mechanisms should be implemented to persuade employees to commit their entire life to the success of the company. More junior staff quit yearly due to poor motivational tips to other rivalry organizations.

\section{Conclusion}

Maximizing profit is the ultimate aim of all business organizations. This reflects to the fact that recruiting employees demands more resource allocation, especially the cost incurred for career development, training, and other HR policies that necessitate success in an organization. Organizations should therefore pay emphasis on ways on how to retain talented and dedicated employees on longer term. The research indicates that improved salary is not the only factors that motivate employees to quit their jobs, but also intrinsic rewards and recognition. Implementing enhance retention strategies that discourages talented employees to leave their jobs should be the primary concern of every organizations. Adopting innovative tech oriented schemes, career development and effective training programmes help to mitigate turnover in an organization. It is vital for organization to retain talented and dedicated employees who invest their energy in making the organization to succeed. This will save the organization expenditure and maximize profits.

One of the key factors why employees quit their jobs in educational institution is attributed to poor communications and managerial policies. It is not normally correct to place new recruits into top management positions, as they lack proper insights into the organizational culture and policies. Most often those new recruits try to completely deviate from the organizational cultures and norms, thereby discouraging those talented workers who have invested their entire energy into making the organization to be what it is of today. This result them quitting and joining rivalry organizations. These de-motivated employees obviously will introduce the managerial skills, trade secrets, and organizational cultures and norms to their new place of work, which will result to tough competition in the job market. It is vital to always allow employees to be promoted in stages based on their commitments and dedications to serving the organization. Therefore, to minimize employee turnover in educational institutions, management should strictly follow best practice to discourage employees to leave their job. Communicating and orientating employees also help to improve retention. For effective management policies, managers are to deployed innovative retention strategies and make key information available to all employees without fair or favour.

\section{Recommendations}

Retaining talented and innovative employees should be the primary concern of any organizations in today's business world. The following are recommendations suggested by the authors:
1. That recruitments should on merit - based using all employment criteria.

2. Management decisions such as promotions, terminations, remunerations, incentives, rewards and other motivational tools should be based on performance rather than favoritism.

3. Communications should flow in both ways; i.e. top bottom and bottom - top approaches. Management should always communicate its priorities to employees and employees in return give feedbacks from senior management can make decisive decisions.

4. Talented and innovative employees should be more motivated to stay put to the effective operations of the organizations and to cut costs of recruiting new employees that will require more fund to recruit, train and invest in them.

5. Management should provide enhance career development and job training for dedicated and committed workers.

6. Management should also motivate employees to be committed to the core values of the organization and provide a conducive environment where individual employees feel as if they are part of the organization's operations.

7. Managers of such organizations should exhibit good leadership qualities and accord respect to their subordinates. Working as an exemplary leader motivate employees to stay put for long time working for an organization.

8. That recruitments should be done by the professional experts: human resource department, who understand the whole process and not by someone at the top who definitely knows nothing about recruitment and hiring.

9. Autonomy should be granted to the HR department in recruiting, promoting, remunerations, terminations, queries, and other management decisions.

10. Job rotation should be instituted to dedicate and innovative employees who contrive the organization's laws instead of terminating his/her contact as a form of punishment, or if aggrieved of ill-treatment from supervisor, they should not leave the decision alone to that particular supervisor.

\section{Acknowledgements}

The authors acknowledge the supports of Prof. Paul Abass Kamara and Professor Roseline Emeh Uyanga at the Institute of Advanced Management and Technology (IAMTECH) for promoting quality education in Sierra Leone. Special appreciation is accorded to the Vice Chancellor and Principal at the Ernest Bai Koroma University of Science and Technology, Prof. Edwin J. J. Momoh for promoting academic research and young talents in the country. Special gratitude goes to the following people: Mrs. Elizabeth GumaSawaneh, Rev. Dr. Momodu Conteh, Apostle Dora Dumbuya, of the Jesus is Lord Ministry, Mr. Williams Lewis and Mrs. Mariama Munu for their moral and financial supports. 


\section{References}

[1] Mitchell, T. R., Holtom, B. C., Lee, T. W., Graske, T. (2001), How to keep your best employees: developing an effective retention policy. The Academy of Management Executive, 15, 96-109.

[2] Kevin, M. M., Joan, L. C., Adrian, J. W. (2004), Organizational change and employee turnover. Personnel Review, 33 (2), 161-166.

[3] Chipunza, C., Samuel, M. O. (2009), Employee retention and turnover: using motivational variables as a panacea. African Journal of Business Management, 3 (8), 410-415.

[4] Zingheim, P. K., Schuster, J. R., Dertien, M. G. (2009), Compensation, reward and retention practices in fast-growth companies. World at Work Journal, 18 (2), 22-39.

[5] Ongori, H. (2007). A review of the literature on employee turnover. African Journal of Business Management, 1 (3), 4954 .

[6] Montgomery, J. D. (2006). The relationship between training and retention in a volunteer organization. PhD Dissertation, Auburn, Alabama: Auburn University. P. 72-77.

[7] Roberts, N., Outley, C. (2002), Innovation and resourcefulness: recruit and retain a diverse staff in the $21^{\text {st }}$ century. Parks and Recreation Magazine, 37 (5), 39-46.

[8] Paul, A. K., Anantharaman, R. N. (2003), Impact of people management practices on organizational performance: analysis of a causal model. International Journal of Human Resource Management, 14 (7), 1246-1266.

[9] Barringer, B. R., Jones, F. F., Neubaum, D. O. (2005). A quantitative content analysis of the characteristics of rapidgrowth firms and their founders. Journal of Business Venturing, 20, 663-687.

[10] Miller, D. (2006), Strategic human resource management in department stores: an historical perspective. Journal of Retailing and Consumer Service, 13 (2), 99-109.
[11] Roberts, J. A., Coulson, K. R., Chonko, L. B. (1999), Salesperson perceptions of equity and justice and their impact on organizational commitment and intent to turnover. Journal of Marketing Theory and Practice, 7, 1-15.

[12] Collins, C. J., Clark, K. D. (2003), Strategic human resource practices, top management team social networks, and firm performance: the role of human resource practices in creating organizational competitive advantage. Academy of Management Journal, 46 (6), 740-751.

[13] Schein, E. (1990), Organizational culture. American Psychologist, 45 (2), 109-119.

[14] Vlachos, I. P. (2009). The effects of human resource practices on firm growth. International Journal of Business Science and Applied Management, 4 (2), 17-34.

[15] Yazinski, S. (2009). Strategies for retaining employees and minimizing turnover. Retrieved from York, NY.

[16] Aquino, K., Griffeth, R. W., Allen, D. G., Hom, P. W. (1997). Integrating justice constructs into the turnover process: A test of a referent cognitions model. Academy of Management Journal, 40, 1208-1227.

[17] Trevor, C. O. (2001). Interactions among actual ease-ofmovement determinants and job satisfaction in the prediction of voluntary turnover. Academy of Management Journal, 44, 621-638.

[18] Jackofsky, E. F. (1984). Turnover and job performance: An integrated process model. Academy of Management Review, 9, 74-83.

[19] Muchinsky, P. M. (1977). Employee absenteeism: A review of the literature. Journal of Vocational Behavior, 10, 316-340.

[20] Lockwood, N. R. (2006). Talent management: Driver for organizational success. 2006 SHRM Research Quarterly. Alexandria, VA: Society for Human Resource Management

[21] Dalton, D. R., \& Mesch, D. J. (1990). The impact of flexible scheduling on employee attendance and turnover. Administrative Science Quarterly, 35, 370-387. 